\title{
INFÂNCIA E CIDADE: PERCEPÇÕES SOBRE O ESPAÇO URBANO ${ }^{1}$ CHILDHOOD AND CITY: PERCEPTIONS ABOUT THE URBAN SPACE
}

\author{
Juliana Lamana Guma², Maria Augusta Scalcon Calil ${ }^{3}$ e Melina Nogueira Hoffmeister ${ }^{4}$
}

\section{RESUMO}

O presente trabalho busca discorrer sobre a relação entre a infância e a cidade, destacando as percepções que as crianças têm sobre o espaço urbano. A temática é objeto de estudo do projeto Brinca na Cidade, apoiado pelo Programa Institucional de Bolsas de Extensão (PROBEX) da Universidade Franciscana e vinculado ao projeto de extensão [com]VIDA. Além disso, o texto aborda o potencial educador das cidades e o envolvimento das crianças no planejamento urbano. Como resultado da discussão, é exposto uma ação elaborada com o intuito de buscar metodologias para diagnosticar a forma como o público infantil se relaciona com o ambiente em que vive e suas percepções sobre os espaços públicos. As atividades realizadas pelo projeto tiveram como referência ações de coletivos urbanos e publicações que reconhecem e reforçam de forma lúdica a descoberta da cidade pela criança enquanto cidadã e pertencente ao espaço urbano.

Palavras-chave: Criança, Educação Urbana, Extensão, Urbanismo.

\section{ABSTRACT}

This paper seeks to discuss the relationship between childhood and the city, highlighting the perceptions that children have about the urban space. The theme is the subject of the project Brinca na Cidade, supported by the Institutional Extension Scholarship Program (PROBEX) of the Universidade Franciscana and linked to the extension project [com]VIDA. Also, the text approaches the educational potential of the cities and the involvement of children in urban planning. As a result of the discussion, an action designed to seek methodologies to diagnose the way children relates to the environment in which they live and their perceptions of public spaces is exposed. The activities carried out by the project were based on the actions of urban collectives and publications that recognize and reinforce in a playful way the discovery of the city by the child as a citizen and belonging to the urban space.

Keywords: Child, Urban Education, Extension, Urbanism.

1 Artigo científico resultado de projeto de extensão.

2 Arquiteta e Urbanista, Mestre em Planejamento Urbano e Regional, docente do curso de Arquitetura e Urbanismo da UFN.

E-mail: juliana.guma@ufn.edu.br

3 Graduanda em Arquitetura e Urbanismo pela Universidade Franciscana. E-mail: maria.augusta@ufn.edu.br

4 Graduanda em Arquitetura e Urbanismo pela Universidade Franciscana. E-mail: melina.hoffmeister@ufn.edu.br 


\section{INTRODUÇÃO}

O [com]VIDA é um projeto extensionista do curso de Arquitetura e Urbanismo da Universidade Franciscana, que iniciou suas atividades em 2018 com o intuito de realizar um estudo de identidade ambiental e urbana do bairro Nossa Senhora do Rosário. No entanto, em 2020, o projeto descentralizou suas ações, abrangendo todo o território de Santa Maria. Além da mudança do local de estudo, o [com]VIDA passou a explorar a temática da educação urbana.

A partir disso, foi aprovado um projeto no Programa Institucional de Bolsas de Extensão (PROBEX) da Universidade Franciscana que aborda os temas infância e cidade, intitulado Brinca na Cidade. A proposta, apresentada neste artigo, teve o objetivo de pesquisar e elaborar ferramentas, objetos e metodologias que reforcem a relação da criança com o espaço urbano de forma lúdica, auxiliando no processo de descoberta da cidade pela criança enquanto cidadã e pertencente ao espaço.

Nesse sentido, a temática encontra relevância na Constituição Federal Brasileira (CF/88) que estabelece, em seu Artigo $6^{\circ}$, que entre os direitos sociais da população está a educação e, no Artigo 205, define a educação como "direito de todos e dever do Estado e da família (...) com a colaboração da sociedade". O mesmo artigo afirma que a educação deve objetivar o "pleno desenvolvimento da pessoa, seu preparo para o exercício da cidadania e sua qualificação para o trabalho".

Este artigo aborda, brevemente, a relação da criança com a cidade e as possibilidades de reconhecer a cidade como espaço educador a partir de práticas urbanas e de planejamento, tendo como base a pesquisa bibliográfica realizada no projeto de extensão Brinca na Cidade. Entre os referenciais práticos e teóricos aqui apresentados é possível destacar o coletivo Rede Ocara, por exemplo, que atua desde 2013 nos países da América Latina com ações que conectam infância e cidade, e o livro “Cidades para Brincar e Sentar” de Meyer e Zimmermann (2020).

Ainda, nos resultados e discussões estão apresentadas duas ações extensionistas desenvolvidas pelo projeto. A primeira que interage com o público infantil, realizada no segundo semestre de 2020, já finalizada, e a segunda, ainda em andamento, que propõe atividades de reconhecimento dos espaços da cidade pelas crianças. É relevante ressaltar que o Brinca na Cidade desenvolveu suas ações no contexto da Pandemia do COVID-19, o que dificulta significativamente o acesso às crianças e escolas, tendo como importante meio de comunicação as redes sociais junto ao projeto [com]VIDA.

\section{A RELAÇÃO DA CRIANÇA COM A CIDADE}

A criança abriu a porta de casa e saiu. O que viu era diferente. (...) Das paredes que encerram a casa, a criança foi para a infinita cidade aprender a compartilhar, a construir, a ser cidadã. Seu universo começou a crescer, e sua aventura também. (ANTUNES, 2018, s/p) 
O encontro da criança com o espaço da cidade revela para ela um mundo de possibilidades de crescimento, aventuras e descobertas, como cita a autora Bianca Antunes no livro Casacadabra (2018). O recorte temático da relação da criança com a cidade tem crescido e vem sendo trabalhado com frequência em projetos e pesquisas.

Atualmente, nota-se que o contato entre as crianças e os espaços urbanos decresce de forma significativa, não só pela atual situação de isolamento social. Conforme Meyer e Zimmermann (2020, p. 25) "diversas pesquisas demonstram que as crianças são prisioneiras em suas próprias casas e perderam significativamente a liberdade de se movimentar com autonomia pela vizinhança onde moram". Tal temática também é abordada no documentário “O começo da vida 2: lá fora” (Terra, 2020), em que se faz referência ao conceito de redução dos horizontes da infância de autoria do filantropo Tim Gill, que afirma que a liberdade das crianças nas cidades foi reduzida ao longo dos anos. Assim, torna-se necessário romper esse paradigma criando oportunidades para que as crianças experienciem a rua.

\footnotetext{
Das mudanças ocorridas na sociedade ao longo do século XX, aquela que se destaca para nós, para fins de análise neste texto, foi a transformação do espaço de convivência da criança de áreas externas como a rua e os terrenos baldios para espaços internos, em grande parte das sociedades atuais. (ARAÚJO, 2016, p. 109-110)
}

Para os adultos e jovens, a cidade por menos acolhedora que seja, ainda é permitido circular de forma autônoma, o que já não é percebido nas crianças. Entre as justificativas está o argumento da segurança, de forma que a elas não é permitido desenvolver sua própria forma de perceber a cidade. Com isso, destaca-se o papel do brincar no desenvolvimento da criança, conforme Dias (2018, p. 105) “o brincar é a expressão da criança, fundamental no seu desenvolvimento". Embora as brincadeiras sejam negligenciadas atualmente na nossa sociedade, acredita-se que elas possuem potencial significativo para contribuírem no aprendizado e na formação do público infantil. Desse modo, cabe às cidades a criação de espaços que estimulem o brincar.

O potencial dos espaços urbanos/lúdicos no desenvolvimento das crianças é extraordinário,
apesar de muitas vezes desvalorizado. Promover às crianças o direito à cidade, à vida urbana
e ao lazer, através do direito de brincar no espaço público, desempenha um papel fundamen-
tal na reprodução da vida social, fortalece os vínculos comunitários, contribuindo para a
construção da cultura infantil, além de ser uma importante ferramenta para forjar uma cultura
de paz e a construção de uma nova cidadania. (DIAS, 2018, p. 108)

Revela-se necessário perceber que não é só a casa e a escola que fornecem espaços para brincar. Tampouco a brincadeira se desenvolve só em praças ou parquinhos exclusivos para as crianças. É preciso que a criança entenda que a cidade como um todo é um espaço lúdico e educativo, ao mesmo tempo em que é preciso que as cidades estejam preparadas para acolher as crianças. 


\section{A CIDADE COMO ESPAÇO EDUCADOR}

Se educar sobre o meio natural é algo que hoje se dá por pressuposto, basta um único dado para entender a importância da educação sobre o meio construído: no ano 2050 sete em cada dez pessoas viverão em cidades. (NAVARRO, 2016, s/p)

Se hoje mais da metade da população mundial vive em aglomerações urbanas, mais de um bilhão são crianças, número que tende a aumentar cada vez mais, reforçando a afirmação acima da autora Virgínia Navarro sobre a importância de educar sobre o espaço urbano. Ainda, segundo a autora, os processos participativos "demonstram a necessidade de que qualquer cidadão possua um mínimo de competências e habilidades espaciais" (NAVARRO, 2016, s/p).

Não se trata de questionar o papel da escola ou das políticas de educação, mas sim de perceber no território potencialidades que auxiliem no processo de construção do indivíduo e de entender a socialização como parte do processo educativo, vivenciado no seu cotidiano.

Deve-se, portanto, destacar o potencial educador das cidades, que pode beneficiar para a formação das crianças, segundo Araújo (2016, p. 108) “as cidades possuem peculiaridades, história, assim como as infâncias das crianças. Em determinados momentos, essas peculiaridades podem se cruzar e formar fatos únicos nessas infâncias. Ela é o principal laboratório que a educação tem à disposição". Acredita-se que, com o desenvolvimento de locais educadores no espaço urbano, estes podem funcionar como complemento à educação restrita ao ambiente escolar.

\footnotetext{
A aprendizagem institucionalizada, como a praticada em muitas escolas e instituições de ensino, não parece ser um campo adequado para que ela se desenvolva, visto que o indivíduo é induzido ou forçada a aprender, em grande parte, por metas de ensino, em meio a padrões curriculares que não correspondem à realidade daquele sujeito, daquela comunidade, aos contextos em que os grupos estão inseridos. (MEYER; ZIMMERMANN, 2020, p. 47)
}

Com isso, destaca-se a importância de promover uma aprendizagem para além da institucionalizada, de forma a incluir as diferentes realidades de cada comunidade. A cidade como espaço educador pode proporcionar a construção coletiva do conhecimento, por meio das trocas de saberes e da conscientização das relações com o mundo por meio de experiências cotidianas. Ainda, considerando o Direito à Educação, assegurado pelo Estatuto da Criança e do Adolescente (2019), os espaços urbanos podem servir de apoio aos espaços tradicionais de ensino, reforçando tal direito.

No Brasil, a experiência da Escola-parque/Escola-classe concebida nos anos de 1940/60 a pelo jurista e educador Anísio Teixeira e os Centros Integrados de Educação Pública (CIEPs) criados por Darcy Ribeiro na década de 1980 são relevantes no contexto de políticas públicas voltadas para a Educação Integral. Ambas extrapolaram o espaço da escola e pensaram nas crianças/jovens enquanto cidadãos defendendo o desenvolvimento do intelecto e do senso crítico dos estudantes. 
A essas experiências somou-se, um conceito extremamente contemporâneo de educação, que encontra eco, sem dúvida, nas propostas de Anísio e Darcy: a ideia da cidade como território educativo, que ganhou força e notoriedade com o Movimento das Cidades Educadoras, iniciado em 1990 com o I Congresso Internacional de Cidades Educadoras, em Barcelona. (COSTA, 2015, p. 13)

Nesse sentido, a educação urbana a partir dos territórios educadores presentes nessas cidades reorganiza com "intencionalidade educativa" os diferentes aspectos que compõem o urbano: "o planejamento urbano; os processos decisórios; a ocupação dos espaços; a gestão dos equipamentos públicos, do meio ambiente, da cultura e das tecnologias". (SINGER, 2015, p. 7).

Outra iniciativa importante, no território brasileiro é o programa Bairro-escola, desenvolvido pela Associação Cidade Escola Aprendiz, que congrega escolas, famílias e comunidades para garantir o aprendizado das crianças e jovens. O programa "interconecta elementos de modo a fomentar um todo integrado: o território educativo" e afirma a "aprendizagem como um processo de conquista de autonomia e postulando a cidade e a comunidade como territórios educativos". (COSTA, 2015, p. 14).

Entre as muitas iniciativas conhecidas hoje, é possível destacar a função importante desempenhada pela Rede Ocara que, de acordo com a plataforma digital do grupo, "Rede Ocara é uma rede latino-americana de experiências e projetos sobre cidade, arte, arquitetura e espaço público nos quais participam crianças". O Rede Ocara busca expor essas experimentações a fim de ajudar e inspirar grupos que realizem estudos semelhantes.

Uma das propostas do coletivo denomina-se "Curativos Urbanos" e consiste na confecção de curativos de cartolina utilizados para demarcar vestígios no espaço urbano que necessitem melhorias, como buracos, rachaduras e locais mal sinalizados. Dessa forma, a atividade atenta para os problemas de mobilidade, contribuindo para a formação da criança de uma maneira lúdica e atrativa.

Algumas publicações relevantes sobre a temática também inspiram novas ações, como é o caso de "Cidades para Brincar e Sentar" de Meyer e Zimmermann (2020), em que são abordadas ações em Griesheim e Bruhl, cidades alemãs em que foram realizadas experimentações envolvendo crianças no planejamento urbano. A obra relata todo o processo de participação do público infantil e reforça a importância desse envolvimento. De acordo com Meyer e Zimmermann (2020, p. 30), “as crianças devem ter a possibilidade de apropriar-se de lugares, ou seja, de construir relações com o ambiente, atribuindo-lhe um cunho próprio e participando ativamente de sua mudança".

No caso de Bruhl, o projeto foi dividido em etapas iniciando-se pela conscientização da população local sobre a importância do envolvimento do público infantil no planejamento das cidades. A seguir, foram desenvolvidas pesquisas e documentações para a formação de um diagnóstico da percepção do público sobre o espaço. Por fim, foi realizado um projeto a partir da identificação dos pontos de interesse. Foram inseridos mobiliário urbano, diferentes texturas e padrões, que são elementos do urbanismo tático. 
O urbanismo tático, prática que vem ganhando destaque nos últimos anos, tem se mostrado uma estratégia atrativa para coletivos ativistas, arquitetos, urbanistas e designers ao redor do mundo por propor, a baixo custo e numa microescala, intervenções urbanas pontuais na intenção de promover o direito à cidade. (MOREIRA, 2019, s/p)

Para tanto, entende-se necessário questionar, entre outras coisas: O que a cidade de hoje ensina? Como a cidade acolhe sua população, principalmente mais jovem? Quais os resultados dessa interação criança X cidade no processo de formação de cidadãos participantes da construção de políticas públicas? Acredita-se que o contato entre infância e espaço urbano deve ser explorado, podendo trazer benefícios para a formação da criança e para o desenvolvimento da cidade.

\section{A CRIANÇA NO PLANEJAMENTO URBANO}

Ao abordar o planejamento urbano contemporâneo, deve-se considerar a teoria de Jan Gehl. O arquiteto e urbanista dinamarquês considera que para planejar cidades melhores e mais convidativas, revela-se fundamental analisar a escala humana, que comumente é negligenciada. Conforme Gehl $(2015$, p. 3) "uma característica comum de quase todas as cidades - independente da localização, economia e grau de desenvolvimento - é que as pessoas que ainda utilizam o espaço da cidade em grande número são cada vez mais maltratadas".

Enquanto não vivemos como Gehl propõe em Cidade para Pessoas, nos deparamos com espaços urbanos pouco convidativos e acolhedores para adultos, no caso das crianças é ainda mais difícil. Segundo Veloso (2018, s/p) a criança é vista como "recém-chegada", nessa sociedade, "aquele indivíduo que ainda não domina com plenitude todos os elementos referentes a ela". As crianças, apesar de nem sempre serem incluídas no planejamento urbano, continuam presentes em grande parte da cidade. A inclusão delas na gestão e planejamento das cidades, se tornaria uma aproximação dupla. Sendo assim, o sujeito criança se apropriaria de conteúdos urbanísticos e o planejamento e a gestão urbana incorporariam uma espacialidade mais significativa a elas. A autora conclui que o recorte "criança" nada mais é que uma delimitação de uma fase da vida que no fundo inclui a todos".

No livro A Cidade como um jogo de cartas (1988), Carlos Nelson Ferreira Santos narra o processo de urbanização de seis novas cidades em Roraima e cita que ali existe uma nova chance de "encontrar os meios para fazer com que conhecimento popular e erudito se encontrem" (SANTOS, 1988, p. 17) tornando a vida urbana mais democrática. O autor afirma, ainda, que a parcela da população mais adequada para ensinar tais conhecimentos relativos à vida urbana são as crianças por serem os “contaminadores" e disseminadores potenciais desse aprendizado junto aos adultos, por serem elas mais receptivas e menos preconceituosas e, por fim, porque elas também irão exercer essa cidadania.

Considerando as particularidades da vivência da criança como cidadã, pensa-se que a participação ativa desta nas decisões que envolvem o planejamento urbano torna-se fundamental. 
Portanto, os espaços de convivência e de permanência existentes, além de todos os outros potenciais de um município, devem ser registrados, avaliados e deve-se definir soluções para que os tornemos facilmente acessíveis e amigáveis às crianças. Por isso, o conhecimento da perspectiva delas, dos adolescentes, dos idosos e das pessoas com mobilidade reduzida precisa ser seriamente levado em consideração. Suas vivências devem ser incluídas de fato no planejamento e organização de ambientes privados, de bairros, das administrações públicas. (MEYER; ZIMMERMANN, 2020, p. 54)

Nesse sentido, a experiência de Medellín se destaca no cenário mundial e demonstra que existem possibilidades para as cidades da América Latina resolverem seus problemas urbanos através de um processo de planejamento coeso, contínuo e que, entre outras importantes ações, entende a cidade como um "ecossistema educativo" que através de "redes pedagógicas" com equipamentos urbanos leva ao território urbano educação e cultura, fazendo da "cidade o cenário universal de aprendizagem e de exercício cidadão". (ISVIMED, 2014, p. 175) Portanto, a partir do reconhecimento da criança/ jovem como ator social fundamental para a construção de cidades mais justas.

Na cidade educadora de Medellín, o grande movimento de articulação urbana se concentra na criação de aproximadamente 30 equipamentos urbanos, ligados a cultura, lazer e atenção comunitária, localizados nas áreas mais frágeis da sociedade que são oriundos dos desejos e aspirações de cada comunidade tendo como orientador e facilitar do processo de criação o corpo técnico das empresas públicas de Medellín. Tais iniciativas estão contempladas no conceito de Urbanismo Social que

deseja promover a melhoria da qualidade de vida urbana e a inclusão sócio territorial, especialmente direcionando investimentos para áreas mais socialmente vulneráveis e para a solução integrada das grandes questões habitacionais urbanas e das infraestruturas de suporte. (LEITE, 2020, p. 1)

Como percebido, algumas cidades têm tido resultados positivos ao reconhecer a criança enquanto ator social e cidadão nas práticas de planejamento urbano. Ainda, que ferramentas e experiências importantes também estão disponíveis aos gestores para pensar cidades mais acolhedoras e educativas. $\mathrm{O}$ que indica um caminho positivo para o desenvolvimento e pesquisa sobre a temática a fim de colaborar com esses processos adequando a realidade de cada cidade.

\section{RESULTADOS E DISCUSSÕES}

Para a criança, exercer a cidadania é poder andar pelas ruas como todos e com todas as demais crianças e adultos, desempenhar os seus deveres e usufruir o espaço público que é de todos. Nesse espaço, a criança adquire o equilíbrio corporal, percebe, conhece, aprende, compara, avalia, escolhe e vivencia o que está ao seu redor. (RIBEIRO, 2014, p. 21)

A partir da discussão sobre a relação da criança com o espaço urbano, foi realizada uma ação juntamente ao projeto de extensão [com]VIDA, com o intuito de incitar reflexões sobre alguns conceitos 
envolvendo a cidade. Com o contexto da pandemia do Covid-19, a atividade foi inteiramente efetuada por redes sociais. Por meio da ferramenta story do Instagram foi compartilhada uma imagem (Figura 1) que convidava o público infantil a responder: “o que é cidade?", “o que é rua?”, “o que é calçada?” e "o que é praça?". Ainda, a proposta foi divulgada com o aplicativo Whatsapp pelos integrantes do projeto [com]VIDA. Conforme Hoffmeister, Calil e Guma (2020, s/p), “o objetivo da atividade era aproximar as crianças da temática da cidade e, ainda, entender a percepção delas sobre esse espaço. Por isso, a ação foi trabalhada de uma maneira simplificada, lúdica e sem restrições, contribuindo para o envolvimento do público infantil”".

Figura 1 - Imagem utilizada para divulgar a ação nas redes sociais

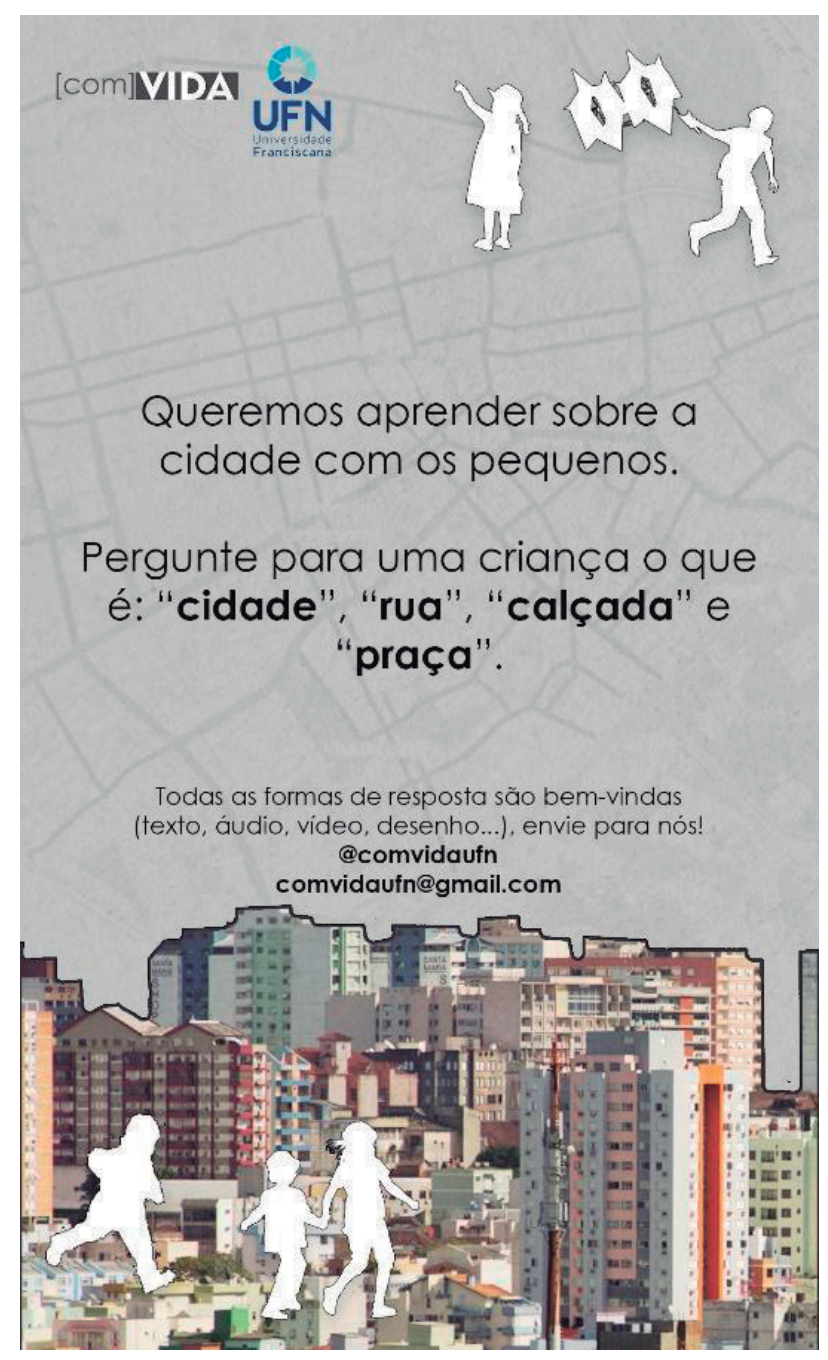

Fonte: Acervo pessoal.

Ao não restringir a tipologia de resposta, a ação aconteceu de uma maneira espontânea e obteve diferentes formas de resposta. Além disso, a simplicidade da proposta contribuiu significativamente para o envolvimento do público. Foram obtidas 52 respostas, 34 em formato de áudio, 10 em formato de texto, 7 em formato de vídeo e 1 em formato de desenho (Figura 2), tendo a participação de crianças de 2 a 13 anos de idade. Por fim, as respostas foram tabuladas para facilitar a análise e discussão. 
Figura 2 - Desenho enviado como resposta da ação

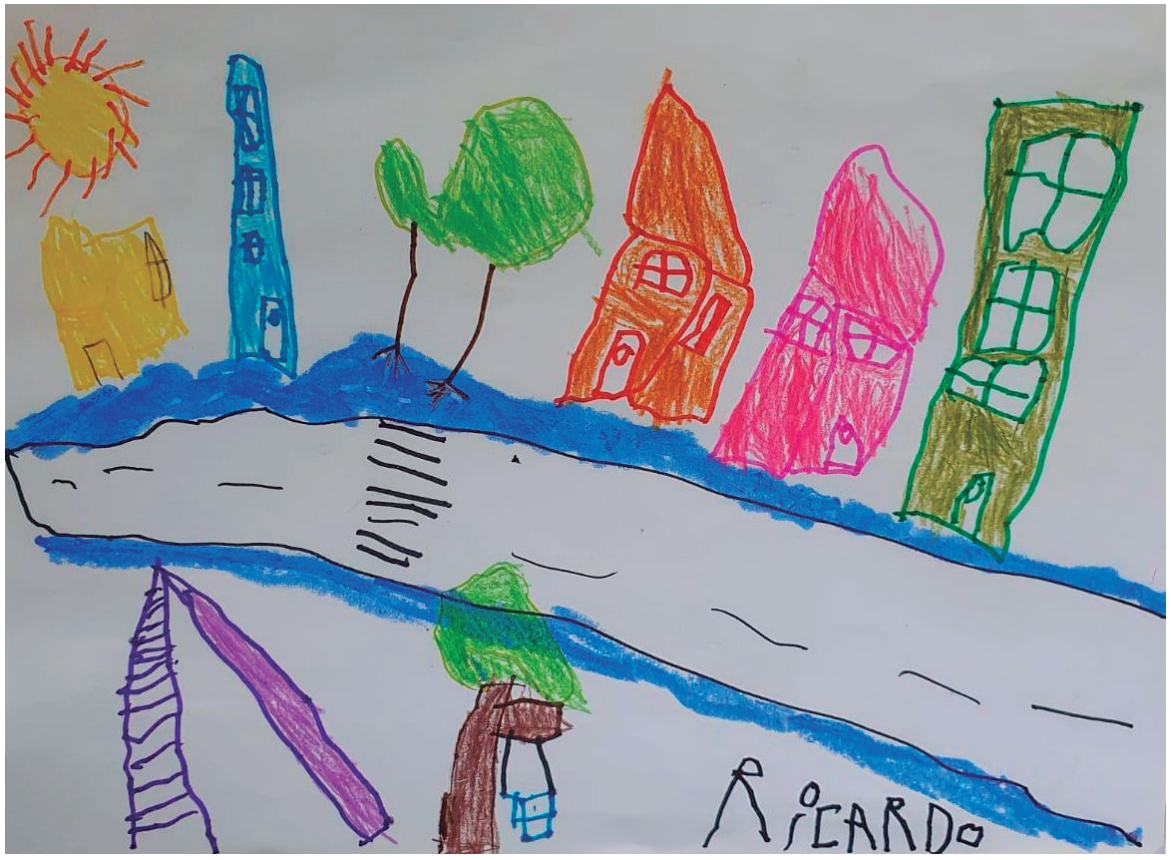

Fonte: Acervo pessoal.

A partir das perguntas lançadas, foi possível entender a percepção do público em relação aos espaços urbanos. O conceito de cidade, frequentemente discutido nos estudos de urbanismo, foi percebido como local de morar, ao encontro disso, existem os estudos sobre o direito à cidade. Segundo Iacovini (2019, s/p) "temos direito de usar, ocupar, produzir, habitar, governar e desfrutar das cidades de forma igualitária". O espaço da rua foi frequentemente associado a perigo e ao uso exclusivo de carros, sendo um local não acolhedor para a escala humana. Isadora de 9 anos de idade respondeu: "rua é onde passa carro, muito carro" e Helena de 3 anos de idade disse: "rua é perigoso". Para a escritora Jane Jacobs (2000, p. 378) “as ruas são destruídas e transformadas em espaços imprecisos, sem sentido e vazios para qualquer pessoa a pé’. Ampliando a discussão, Bernhard Meyer afirma que não só as crianças sofrem a negação do espaço da rua, mas também idosos e pessoas com mobilidade reduzida.

A redução da rua às funções de circulação de motoristas, ciclistas e pedestres ignora as necessidades de crianças, idosos e pessoas com mobilidade reduzida. Dessa maneira, lhes é retirada, sem reflexão, a base para os processos de apropriação, de decisão e de comunicação que desenvolvem e sustentam a vida. Se o espaço da rua não possui essa qualidade, esses grupos evitam cada vez mais ficar em frente à porta de casa. (MEYER, 2020 p. 17)

Essa ausência de acolhimento e de identificação com a cidade e a rua somada a sensação de insegurança que mesmo o espaço da calçada provoca, retiram as pessoas do espaço urbano tornando ainda mais difícil sua apropriação. Em contrapartida, a calçada e a praça foram entendidas, na maioria das respostas, como receptivas para pedestres e propícias para experiências de lazer e convivência. Para Gabriela de 6 anos de idade: "calçada é lugar que você anda, em vez de andar no meio da rua 
e ir para o hospital" e para Pedro de 9 anos de idade: "praça é o que tem uma árvore e calçada, uma quadra inteira onde as pessoas tomam chimarrão e brincam".

Por fim, para realizar o fechamento da atividade e produzir um material de retorno para os participantes, foi desenvolvido um vídeo, divulgado por meio das redes sociais do projeto, abordando os conceitos trabalhados de uma forma lúdica e contendo alguns dos áudios recebidos pelas crianças. Desse modo, acredita-se que a ação será recordada pelos participantes mais facilmente e proporcionará uma aproximação com a temática.

A partir dessa ação, sentiu-se a necessidade de criar novas formas de aproximar as crianças da temática urbana no contexto da pandemia. Com isso, foram elaboradas três atividades, baseadas nos estudos de caso do livro Cidades para Brincar e Sentar (2020), que estão sendo aplicadas por duas escolas municipais de Santa Maria, com o apoio das professoras das séries iniciais. Até o momento as atividades foram disponibilizadas para as escolas, mas ainda não retornaram com as respostas dos alunos.

O primeiro exercício, denominado Intervenção Urbana, consistiu em disponibilizar uma foto da região da escola trabalhada e propor que as crianças interajam com a imagem da maneira que desejassem para tornar o espaço mais atrativo (Figura 3). Assim, torna-se possível estimular a criatividade do público e identificar quais elementos eles gostariam que fossem mais presentes nos espaços urbanos. Para o segundo exercício, o Mapa Afetivo, foi disponibilizado um mapa do local e uma tabela, a ideia é que as crianças identifiquem cinco locais no mapa e preencham na tabela como elas se sentem em cada um desses locais. Para tornar a atividade mais atrativa e de fácil compreensão, foram utilizadas figurinhas na tabela (Figura 4). Desse modo, a atividade tem o intuito de introduzir o trabalho com mapas, estimular o senso de localização e diagnosticar a relação do público com os espaços. Enfim, no último exercício, denominado Rabisco Urbano, é proposto que o público desenhe um local da região da escola que goste e um local que não goste (Figura 5). Dessa forma, a atividade diagnostica a relação das crianças com o entorno.

Como fechamento da ação, espera-se que a partir do retorno dos alunos participantes seja possível tabular e analisar as percepções deles sobre os espaços urbanos do entorno dos ambientes escolares trabalhados. Com isso, será possível compreender quais elementos são necessários para projetar cidades mais acolhedoras para crianças. Por fim, para aumentar o alcance das atividades elaboradas, pensa-se em disponibilizar o material para download por meio das redes sociais do projeto [com] VIDA. Desse modo, os exercícios estarão disponíveis para serem realizados de maneira independente em qualquer escola, auxiliando diversas crianças, e seus cuidadores e professores, a refletirem sobre a cidade e a se perceberem como cidadãs. 
Figura 3 - Material disponibilizado para a atividade de Intervenção Urbana

\section{Intervenção Urbana instruções \\ Para a atividade \#IntervençãoUrbana, você deve desenhar na foto da região da sua escola para tornar o espaço \\ 1. Separe os materiais necessários urbano mais divertido.
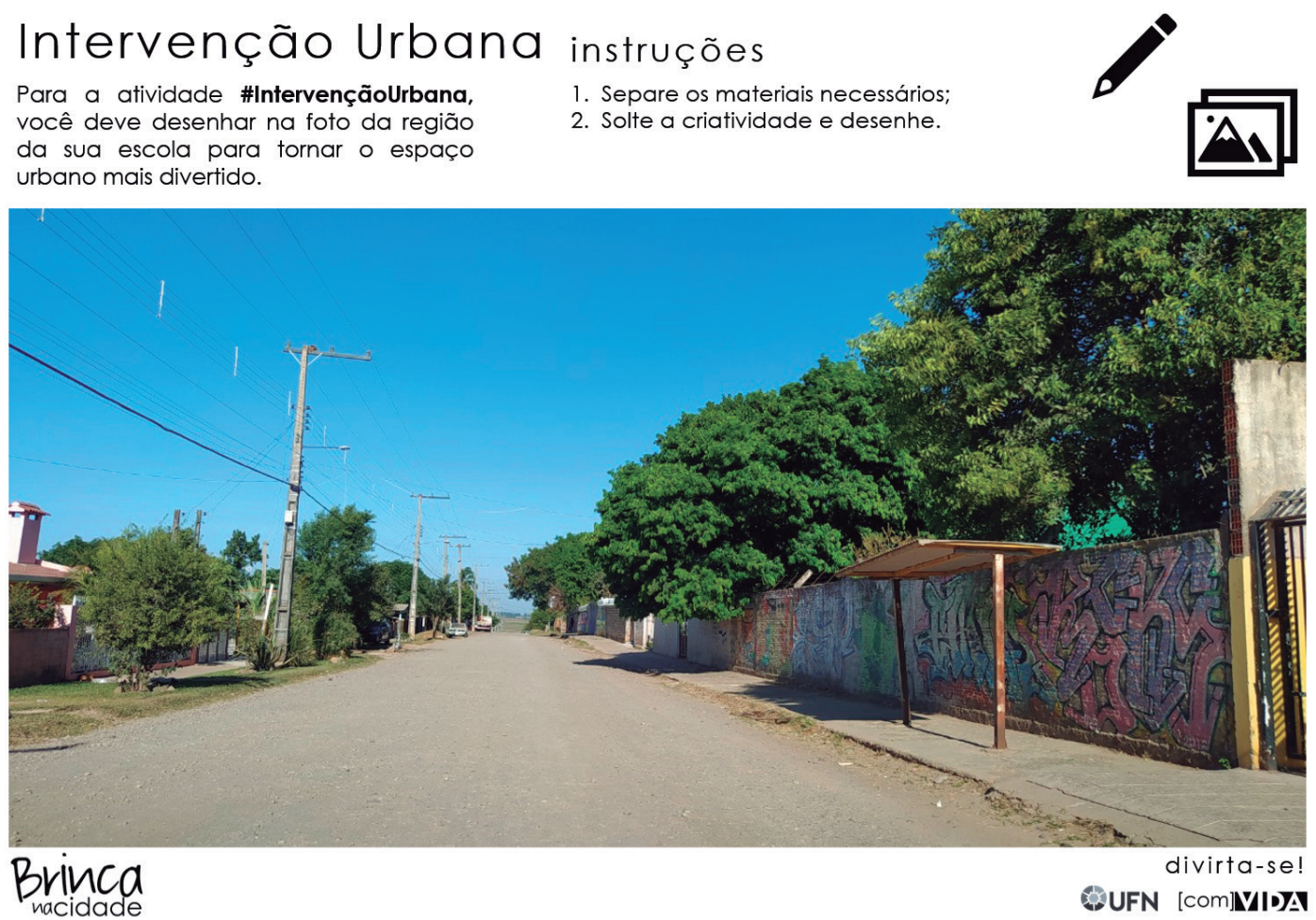

Fonte: Acervo pessoal.

Figura 4 - Material disponibilizado para a atividade Mapa Afetivo.

\section{Mapa Afetivo}

Para a atividade \#MapaAfetivo, avalie como você se sente em relação aos locais da região da sua escola.

\section{instruções}

1. Escolha 5 locais no mapa e numere-os de 1 a 5 ;

2. Identifique os locais na tabela e marque o emoji que mais representa como você se sente naquele espaço.

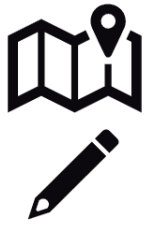

mapa

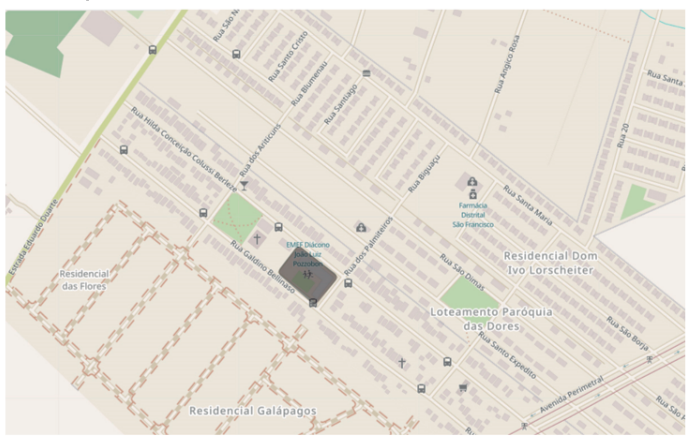

Brinca

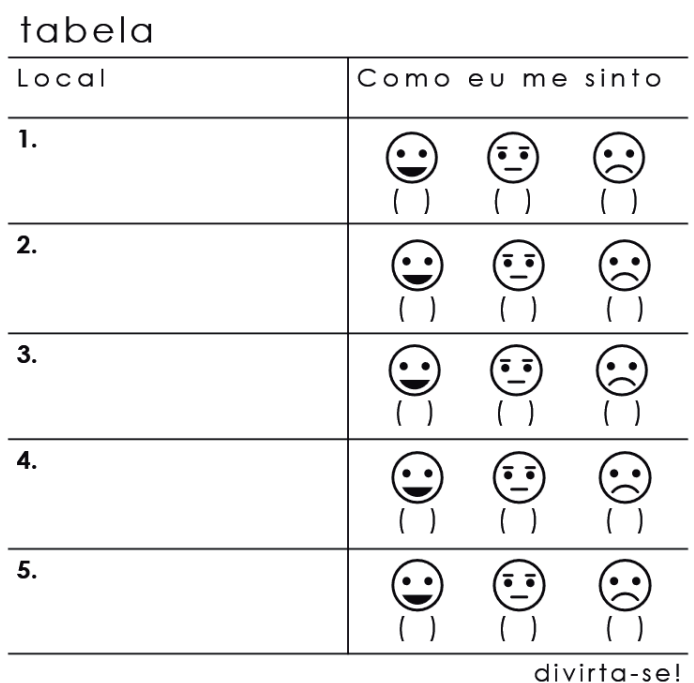

QUFN [com]V/D]

Fonte: Acervo pessoal. 
Figura 5 - Material disponibilizado para a atividade Rabisco Urbano

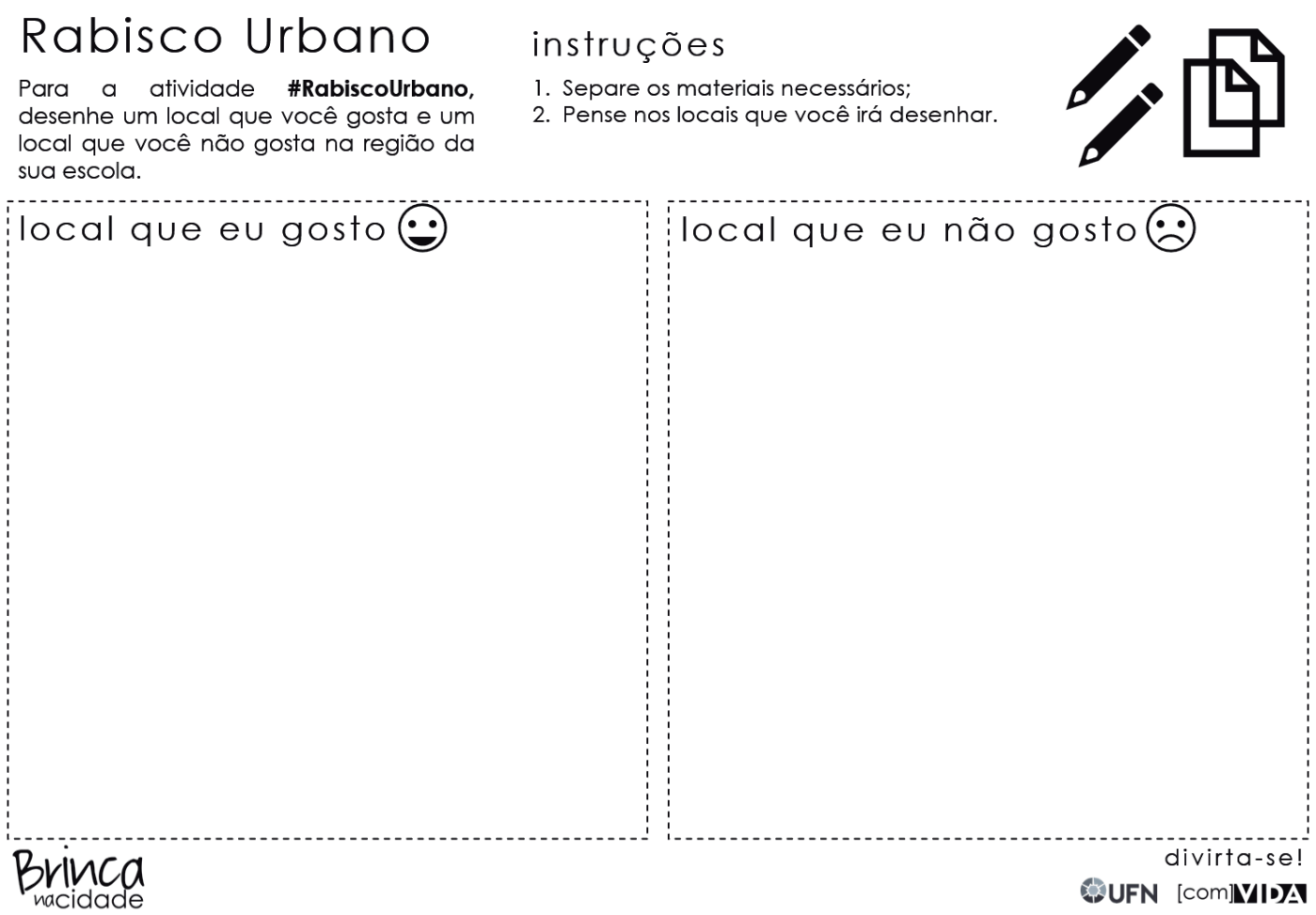

Fonte: Acervo pessoal.

\section{CONSIDERAÇÕES FINAIS}

Esse assunto é democrático por excelência. Saber sobre a cidade é ser dono das suas regras de formação e desenvolvimento. Por isso, elas têm que ser obrigatoriamente muito simples para que todos possam jogar. (SANTOS, 1988, p. 186)

Reforçando a afirmação acima, entende-se que o reconhecimento da criança como ator social nos processos de planejamento urbano é positivo para o desenvolvimento da cidade e da sociedade pois auxiliará na melhoria da qualidade de vida e um aumento da justiça social - conceitos, então, complementares e dependentes pois sem justiça social não há qualidade de vida e vice-versa. Para Souza (2013, p. 66), esses conceitos são alcançados “(...) quando os próprios indivíduos e grupos específicos definem os conteúdos concretos e estabelecem as prioridades" respeitando a "autonomia individual e coletiva enquanto princípio e parâmetro" do planejamento urbano e da vida na cidade.

Por fim, com base nos estudos desenvolvidos, revela-se possível destacar a importância do tema da relação da infância e da cidade para o cenário contemporâneo. Ao introduzir as temáticas urbanas desde cedo na vida das pessoas o sentimento de pertencimento e de comunidade é reforçado, de acordo com Silva (2013, p. 199) "buscar a identidade e o sentimento de pertença de um lugar é procurar compreender o entrelaçar das falas e conceitos que dão forma aos espaços”. Assim, ao formar cidadãos conscientes de seu pertencimento no ambiente em que vivem, as cidades terão espaços mais 
humanos. Conforme Gehl (2015, p. 118), “cidades que propiciem boas condições para que as pessoas caminhem, parem, sentem-se, olhem, ouçam e falem".

\section{REFERÊNCIAS}

ANTUNES, Bianca. SAYEGH, Simone. CASACADABRA, Cidades para brincar. São Paulo: Pistache, 2018.

ARAÚJO, Ana Lucia Castilhano. Infância e cidade: reflexões sobre espaço e lugar da criança. Caderno de Filosofia e Psicologia da Educação da UESB, p. 107-127, 2016.

BRASIL. Constituição Federal. Brasília, DF: 1988

DIAS, Mariana. Em busca dos espaços públicos de brincar: um estudo das infâncias contemporâneas na cidade de Vitória-ES. Pós. Revista do Programa de Pós-Graduação em Arquitetura e Urbanismo da FAUUSP, v. 25, n. 45, p. 102-117. Acesso em: 27 abr. 2018.

GEHL, Jan. Cidades para Pessoas. 3. ed. São Paulo: Perspectiva, 2015.

HOFFMEISTER, Melina. CALIL, Maria Augusta. GUMA, Juliana. A criança e a cidade: percepções sobre o espaço urbano. In: SEPE: SIMPÓSIO DE ENSINO, PESQUISA E EXTENSÃO, 24. 2020. Anais... Acesso em: 25 nov. 2020.

IACOVINI, Rodrigo. Por uma nova ordem do espaço público: o direito à cidade para todos. ArchDaily Brasil, out. 2019. Disponível em: https://bit.ly/3plIPMC. Acesso em: 15 set. 2020.

ISVIMED. Carta de Medellin - sobre o porvir humano das urbes do mundo. Alcadia de Medellin/ Sétimo Forum Urbano Mundial ONU - Habitat, Instituto social de vivienda y hábitat. Medellin: Alcadia de Medellin. 2014.

JACOBS, Jane. Morte e vida das grandes cidades. São Paulo: Martins Fontes, 2000.

LEITE, Carlos. O financiamento da cidade e o Urbanismo Social. Disponível em: https://bit.ly/ 3nbmXRh. Acesso em: 23 nov. 2020. 
MEYER, Bernhard. ZIMMERMANN, Stefanie. Cidades para Brincar e Sentar. 1. ed. São Paulo: Alana, 2020.

MOREIRA, Susanna. O que é Urbanismo Tático?. ArchDaily Brasil, 6 dez. 2019. Disponível em: https://bit.ly/3B81xK9. Acesso em: 19 fev. 2021.

RIBEIRO, Marieta Colucci. A Criança no Espaço Urbano: Caminhos Escolares. 2014. Monografia (graduação), Arquitetura e Urbanismo, Faculdade de Arquitetura e Urbanismo da Universidade de São Paulo. FAU-USP: São Paulo, 2014.

NAVARRO, Virgínia. Por que ensinar arquitetura para as crianças? Traduzido por Julia Daudén. Archdaily, 2016. Disponível em: https://bit.ly/31YdSfz. Acesso em: jul. 2020.

O COMEÇO DA VIDA 2: lá fora. Direção de Renata Terra. Brasil: Netflix, 2020. (92 min)

REDE OCARA. Sítio oficial. Disponível em: https://www.redocara.com/. Acesso em: abr. 2021.

SANTOS, Carlos Nelson F. A cidade como um jogo de cartas. Niterói: Universidade Federal Fluminense: EDUFF; São Paulo: Projeto Editores, 1988.

SILVA, Michelle. Identidade, pertencimento e sociabilidade no espaço urbano: observações sobre a percepção dos usuários do bairro Cidade Baixa em Porto Alegre. Iluminuras, Porto Alegre, v. 14, n. 34, p. 194-210, ago./dez. 2013.

SOUZA, Marcelo José Lopes de. Mudar a Cidade: uma introdução crítica ao planejamento e a gestão urbanos. Rio de Janeiro: Bertrand Brasil, 2013.

VELOSO, Marília Tules. Crianças na cidade - participação infantil no planejamento e gestão das cidades: novas espacialidades, autonomia, possibilidade. 2018. 302 f. Dissertação (Mestrado em Programa de Pós-Graduação de Arquitetura e Urbanismo) Escola de Arquitetura da Universidade de Minas Gerais, Belo Horizonte, 2018. 